\title{
Quality of life and psychological functioning in pediatric obesity: the role of body image dissatisfaction between girls and boys of different ages
}

\author{
Maria João Gouveia • Roberta Frontini • \\ Maria Cristina Canavarro • Helena Moreira
}

Accepted: 1 May 2014

(C) Springer International Publishing Switzerland 2014

\begin{abstract}
Purpose This study aims to explore the associations between weight status, body image dissatisfaction (BID), and psychosocial adjustment [quality of life (QOL), internalizing and externalizing problems] of normal-weight and obese youth. It aims to explore whether the associations between weight status and psychosocial adjustment are mediated by BID as well as the moderating role of youth's age and gender on these associations.

Methods The sample comprised 260 children and adolescents aged 8-18 years with normal weight $(n=128)$ and obesity $(n=132)$. All of the participants completed self-report instruments, including the KIDSCREEN-10, Strengths and Difficulties Questionnaire, and Collins Body Image scale.

Results Obese youth, regardless of gender, reported poorer QOL, more internalizing/externalizing problems, and higher rates of BID compared with their normal-weight counterparts. BID mediated the relationship between weight status and QOL, but only for youth above 12-year old. The relationship between weight status and internalizing/externalizing problems was direct and independent of youth's age and gender.

Conclusions Pediatric obesity is associated with poorer psychosocial outcomes, which underlines the need for preventive and early interventions. An important target in psychological interventions seems to be BID, which proved to be an important mechanism linking obesity and decreased QOL among adolescents.
\end{abstract}

M. J. Gouveia · R. Frontini · M. C. Canavarro · H. Moreira $(\square)$ Faculty of Psychology and Educational Sciences, CognitiveBehavioral Research Centre, University of Coimbra, Rua do Colégio Novo, Apartado 6153, 3001-802 Coimbra, Portugal

e-mail: hmoreira@fpce.uc.pt
Keywords Pediatric obesity - Quality of life · Psychological functioning · Body image dissatisfaction

\section{Introduction}

Obesity is a major public health problem among youth, both worldwide and in Portugal [1]. The prevalence of pediatric obesity has increased tremendously over the past two decades [2], with current estimates indicating that approximately $20 \%$ of 11-year-old Portuguese children and 15 and $19 \%$ of 15-year-old Portuguese adolescent girls and boys, respectively, are obese [1]. This high prevalence is concerning because pediatric obesity is associated with negative consequences for youth's physical health [3] and psychosocial adjustment [4-6]. Poorer psychosocial outcomes have been related to challenges and difficulties that obese youth may face. For instance, obese youth report higher rates of stigmatization and higher levels of intolerance and prejudice from others, including their educators and parents, than do their normal-weight peers [7, 8]. Moreover, obese youth frequently face social exclusion and are less likely than their normal-weight peers to be nominated as friends $[9,10]$. Therefore, it is not surprising that the psychosocial adjustment of obese youth, particularly their quality of life (QOL) $[4,9,11-14]$ and psychological functioning $[6,15,16]$, is frequently compromised.

When compared with normal-weight youth, youth with obesity tend to report significantly worse QOL in several domains [12, 17-19]. Some studies have even found that the QOL of treatment-seeking obese youth is similar to that of youth with cancer [18] and is lower than that of youth with other chronic conditions [20]. Far less attention has been devoted to the psychological functioning of obese 
youth in terms of both externalizing (e.g., conduct problems, hyperactivity) and internalizing problems (e.g., depression, social withdrawal) [15]; further, inconsistent results have been found for these adjustment outcomes. Some studies have reported higher levels of psychopathology in obese youth, particularly in weight management programs, in comparison with their normal-weight peers $[16,19-22]$ or in comparison with youth with other chronic conditions, such as diabetes [20,23] or asthma [20]. However, other studies, mainly those focused on depressive and internalizing symptomatology [9, 19], have reported that obese youth exhibit average symptomatology and that only a small subset reports clinically significant symptoms or meets the diagnostic criteria for depressive disorder [17]. Externalizing problems have been investigated less frequently, although a few studies have provided the evidence of a relationship between behavioral problems and obesity [24, 25].

Previous studies have suggested that the impact of weight status on psychosocial functioning might be moderated by the youth's gender and age. Stronger associations between overweight and poor psychosocial functioning have been consistently found among girls than among boys $[26,27]$. The moderating role of the developmental stage remains less understood, although some studies have provided evidence of developmental differences. For instance, Swallen et al. [14] found a stronger association between weight status and psychological functioning among younger adolescents (12-14 years) than older cohorts (15-20 years). To the best of our knowledge, this association has not been examined in samples with wider age ranges (i.e., comprising both children and adolescents), which precludes an adequate examination of the moderating role of age.

Despite the increasing number of studies on the psychosocial adjustment of obese youth, little is known about the factors that may account for the relationship between weight status and psychosocial adjustment. The current study focuses on the role of body image dissatisfaction (BID) as a potential mediator. Several studies have found that obese youth are at an increased risk of BID in comparison with their normal-weight peers [28-30]. A recent meta-analysis comparing youth with and without chronic conditions demonstrated that obese youth have significantly higher rates of BID than most youth with other conditions [31]. The higher prevalence of appearance concerns among obese youth may be related to the strong social pressure to be thin (for girls) and to be muscular (for boys) [29] and to the social stigma obese youth frequently face $[7,8]$. BID may also result from negative parental opinions about body weight or from weight-related teasing by peers, contributing to the development of a "thinness schema" [32].
Numerous studies, mainly conducted among normalweight youth, have attempted to clarify age and gender differences in BID. There is some evidence that although school-age children may already demonstrate discontentment with their body shape, given the social messages they frequently receive from important others, peers, or media about socially accepted body size and shape [33], BID increases substantially in adolescence [34, 35]. During adolescence, there are several unique biological and psychosocial challenges (e.g., puberty-related changes, school transitions) that may negatively influence individual psychosocial adjustment $[1,20]$ and contribute to a heightened dissatisfaction with appearance $[34,36]$. Gender differences have also been found, with girls reporting higher levels of BID than boys [33, 37]. In general, girls are more likely to worry about thinness, whereas boys tend to be concerned with their weight and muscularity $[33,38,39]$.

It has been suggested that higher BID is associated with several negative outcomes, such as eating disorders [40], social anxiety, low self-esteem [31, 41], anxiety, and depression [42] among normal-weight youth. However, little is known about the link between BID and the psychosocial adjustment of obese youth at different ages. Shin and Shin [30] found that higher BID mediated the association between weight status and self-esteem in obese children aged between 10 and 12 years. Obese adolescents with elevated weight and shape concerns are also more likely to report depressive/anxious symptoms, and poor QOL than obese adolescents who do not report these concerns [43]. Similarly, Allen et al. [44] found that weight and shape concerns mediated the relationship between BMI and self-esteem, BID, and depression among obese youth.

\section{The present study}

The present study aims to examine the indirect effect of weight status on youth's psychosocial adjustment through BID and to determine whether the proposed mediation model was moderated by youth's age and gender. We hypothesize that being obese is associated with lower QOL as well as increased internalizing and externalizing problems through higher levels of BID. Additionally, we expect the proposed associations to be stronger among girls and adolescents.

In examining these associations, this study intends to overcome some important limitations of previous research. First, it aims to illuminate a possible mechanism linking weight status and psychosocial adjustment and, hence, to identify a potential target for intervention, adding to the scarce literature on mediators that may explain the aforementioned associations. Second, the vast majority of studies have focused on specific development stages, and in some cases, studies have considered different 
developmental stages together, ignoring differences that may result from varied maturational issues or developmental tasks. This study provides an innovative contribution by examining the moderating role of youth's age on the proposed associations in a sample with a wide age range. This approach allows for a more comprehensive understating of psychosocial functioning in obese youth at different development stages. Third, although gender differences have been widely described in samples of normalweight youth, less is known about the extent to which gender moderates the associations between weight status, BID, and psychosocial adjustment in samples including obese youth. Fourth, previous studies have focused almost exclusively on one indicator of youth's psychosocial adjustment. In this study, we examine the QOL and the psychological functioning of obese youth, allowing for a more complete picture of their adjustment.

\section{Methods}

\section{Participants}

A total sample of 260 youth between the ages of 8 and 18 years was recruited. Of these, 128 were normal weight (BMI: 5th-84th percentile), and 132 were obese (BMI $\geq 95$ th percentile) according to the CDC growth curves [45]. The following inclusion criteria were considered: (1) age between 8 and 18 years; (2) ability to understand and answer the questionnaires; (3) no serious mental illness or developmental delay; (4) absence of genetic syndromes for which obesity is comorbidity; and (5) absence of chronic health conditions among normal-weight youth.

\section{Procedure}

Children and adolescents with obesity were recruited through the nutrition outpatient services of two public pediatric hospitals in the central region of Portugal between May 2012 and April 2013. The Ethics Committee and the Direction Boards of both hospitals approved the study. These youth were participating in a medical weight management program consisting of three elements: (1) nutrition and physical activity education; (2) prescribed diet and exercise plans; and (3) behavior modification. This nonstructured program is tailored according to the specific needs of each youth, which is followed until the initially established weight loss is achieved. The inclusion criteria for entry into the program were a clinical diagnosis of overweight or obesity and age until 18 years. After the nutrition consultation, a research assistant explained the study to the youth and/or their parents and requested their participation. Parents and adolescents aged 14 years and above provided written informed consent, and children under 14-year old provided verbal assent. The participants subsequently completed the questionnaires in a consultation office provided for this purpose. The research assistant was available to assist them whenever necessary.

A community sample of normal-weight youth was collected through three Portuguese public schools. Youth who were overweight/obese $(n=27)$ were excluded from the study. Teachers from several classes were contacted by the researchers, informed about the study, and asked to serve as intermediaries between the researchers and the families. The teachers gave the parents a letter explaining the study and the informed consent form. Those who returned the informed consent received the questionnaires to complete at home and return a week later.

Measures

Participants completed a battery of self-report measures. Reliability measures are presented in Table 2.

\section{Generic $Q O L$}

The Portuguese self-report version of the KIDSCREEN-10 index [46, 47] was used to assess the youth's QOL. This instrument contains ten items answered on a five-point Likert response scale ranging from 1 (never; not at all) to 5 (always; extremely), with higher scores indicating better QOL.

\section{Psychological functioning}

Youth's psychological adjustment was assessed using the difficulties subscale of the Portuguese self-report version of the Strengths and Difficulties Questionnaire (SDQ) [48, 49]. This subscale comprises 20 items that were clustered into internalizing and externalizing problems according to the recent recommendations [50]. Respondents use a threepoint Likert scale ranging from 0 (not true) to 2 (certainly true), with higher scores indicating more problems.

\section{Body image dissatisfaction}

A pictorial instrument with child and adolescent figures was used to assess the youth's BID [51]. This instrument is composed of a set of seven male or female figures adapted to the youth's age illustrating body weight ranging from 1 (very thin) to 7 (obese). Each participant is asked to indicate the figure that looks most like him/herself (real self) and the figure that shows the way he/she would like to look (ideal self). The absolute difference between the score for the real self and the score for the ideal self was used as a measure of BID. Positive scores indicate the desire to lose 
weight, and negative scores indicate the desire to gain weight.

\section{Socio-demographic and clinical characteristics}

Socio-demographic information included the youth's age, gender, and presence of chronic health conditions. The weight and height of the normal-weight youth were selfreported by the parents of children under 14 years and by adolescents, and the weight and height of obese youth were objectively measured by the nutritionist. Using weight $(\mathrm{kg})$ and height $(\mathrm{cm})$ values, BMI was calculated for each individual according to the following formula: weight/ [height $]^{2}$.

Data analysis

The data were analyzed using SPSS version 20.0. Differences between obese and normal-weight youth in sociodemographic characteristics were analyzed through chisquare tests and one-way ANOVAS. Correlations between socio-demographic and study variables were performed to identify potential covariates. To examine whether the hypothesized direct and indirect effects of weight status (independent variable-IV; $0=$ normal weight; $1=$ obesity) on youth's adjustment (dependent variable-DV) through BID (mediator-M) were moderated by youth's age and gender $(0=$ boys; $1=$ girls $)$, conditional process analyses were conducted with the PROCESS computation tool [52]. As demonstrated in Fig. 1, three models were estimated, one for each DV, in which the moderators were hypothesized to affect the path linking the IV and the M (path $a$ ), the path linking the M and the DV controlling for the effect of the IV (path $b$ ), and the direct effect from the IV to the DV holding constant the mediator (path $c^{\prime}$ ). Therefore, six interactions were tested in each model (weight status $\times$ age and weight status $\times$ gender in paths $a$ and $c^{\prime}$; $\mathrm{BID} \times$ age and $\mathrm{BID} \times$ gender in path $b$ ). Prior to model estimation, the variables used in the construction of the products were mean-centered to make the regression coefficients for the DV and M more easily interpretable. In the absence of a significant interaction in one or more paths, the models were re-estimated after the removal of nonsignificant interactions (gender was excluded from all the models because no significant interaction was found). Interactions involving a component of an indirect effect were probed by estimating the conditional indirect effect at the values of youth's ages corresponding to the 10th, 25th, 50th, 75th, and

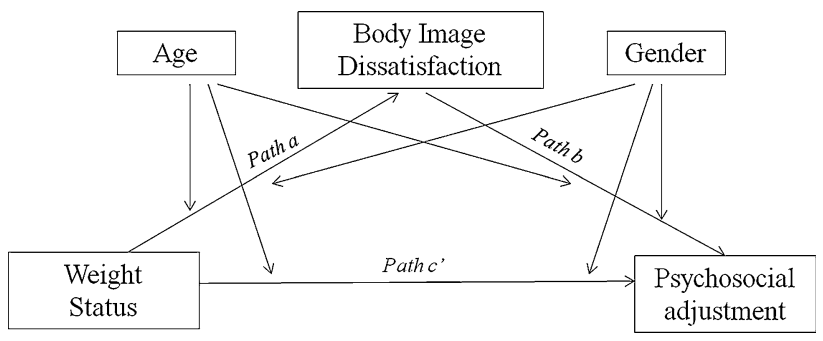

Fig. 1 Conceptual diagram of the moderated mediating models under study

Table 1 Demographic, weight, and clinical characteristics of children and adolescents $(N=260)$

\begin{tabular}{|c|c|c|c|}
\hline & $\begin{array}{l}\text { Normal weight } \\
n=128\end{array}$ & $\begin{array}{l}\text { Obesity } \\
n=132\end{array}$ & $F / p / X^{2} / p$ \\
\hline Age (years) $M(\mathrm{SD})$; range & $12.07(3.29) ; 8-18$ & $12.92(2.68) ; 8-18$ & $5.19 / .02$ \\
\hline \multicolumn{4}{|l|}{ Age group $n(\%)$} \\
\hline Children (8-12 years) & $69(53.90)$ & $62(47.00)$ & \multirow[t]{2}{*}{$1.25 / .26$} \\
\hline Adolescents (13-18 years) & $59(49.10)$ & $70(53.00)$ & \\
\hline \multicolumn{4}{|l|}{ Gender $n(\%)$} \\
\hline Male & $51(39.80)$ & $63(47.70)$ & \multirow[t]{2}{*}{$1.64 / .20$} \\
\hline Female & $77(60.20)$ & $69(52.30)$ & \\
\hline BMI $M(\mathrm{SD})$; range & 18.25 (2.56); 12.24-24.46 & 29.47 (4.10); 21.03-40.56 & $684.90 /<.001$ \\
\hline \multicolumn{4}{|c|}{ Presence of comorbid chronic conditions $M(\mathrm{SD})$} \\
\hline Yes & $0(0.00)$ & $30(22.7)$ & \multirow[t]{2}{*}{$32.89 /<.001$} \\
\hline No & $128(100.00)$ & $102(77.3)$ & \\
\hline \multicolumn{4}{|c|}{ Comorbid chronic conditions $n(\%)$} \\
\hline Asthma/breathing problems & - & $19(14.4)$ & \\
\hline Heart diseases & - & $6(4.5)$ & \\
\hline Epilepsy & - & $2(1.5)$ & \\
\hline Diabetes & - & $2(1.5)$ & \\
\hline Others & - & $1(0.8)$ & \\
\hline
\end{tabular}


Table 2 Descriptive statistics and correlations between demographic and study variables $(N=260)$

\begin{tabular}{|c|c|c|c|c|c|c|c|c|c|c|c|c|c|c|}
\hline \multicolumn{2}{|c|}{ Variables } & \multicolumn{3}{|c|}{$\begin{array}{l}\text { Normal-weight } \\
n=128\end{array}$} & \multicolumn{3}{|c|}{$\begin{array}{l}\text { Obesity } \\
n=132\end{array}$} & \multirow[t]{2}{*}{1} & \multirow[t]{2}{*}{2} & \multirow[t]{2}{*}{3} & \multirow[t]{2}{*}{ Age } & \multirow[t]{2}{*}{ Gender } & \multirow[t]{2}{*}{$\begin{array}{l}\text { Comorbid } \\
\text { condition }\end{array}$} & \multirow[t]{2}{*}{ BMI } \\
\hline & & $M$ & SD & $\alpha$ & $M$ & SD & $\alpha$ & & & & & & & \\
\hline 1 & Quality of life & 79.43 & 12.49 & .77 & 72.25 & 12.42 & .65 & - & & & $-.36^{*}$ & $-.14 *$ & -.09 & $-.37 * *$ \\
\hline 2 & $\begin{array}{l}\text { Internalizing } \\
\text { problems }\end{array}$ & 5.01 & 2.98 & .68 & 6.27 & 2.96 & .67 & $-.42 * *$ & - & & -.01 & $.12 *$ & .07 & $.21 * *$ \\
\hline 3 & $\begin{array}{l}\text { Externalizing } \\
\text { problems }\end{array}$ & 4.71 & 2.86 & .67 & 6.81 & 3.22 & .69 & $-.33 * *$ & $.35^{* *}$ & - & .01 & $-.15^{*}$ & .06 & $.27 * *$ \\
\hline 4 & $\begin{array}{l}\text { Body image } \\
\text { dissatisfaction }\end{array}$ & 0.06 & 0.82 & - & 1.98 & 1.05 & - & $-.30 * *$ & $.16^{* *}$ & $.26 * *$ & $.12^{\dagger}$ & $.12^{\dagger}$ & $.20 * *$ & $.74 * *$ \\
\hline
\end{tabular}

Gender: $0=$ boys; 1 = girls; comorbid conditions: $0=$ no; 1 = yes

Higher scores on quality of life indicate a better quality of life; higher scores on internalizing and externalizing problems indicate higher levels of problems; positive scores on body image dissatisfaction indicate more dissatisfaction

$\dagger p<.06 ; * p<.05 ; * * p<.01$

90th percentiles of the distribution, using a bootstrapping procedure $(10,000$ samples). This procedure creates $95 \%$ bias-corrected and accelerated confidence intervals (BCaCIs). An indirect effect is significant if zero is not contained within the lower and upper CIs. Similarly, if the direct effect was moderated by age, conditional direct effects at the 10th, 25th, 50th, 75th, and 90th percentiles of age were estimated.

\section{Results}

Descriptive statistics and correlations

The youth's demographic characteristics are presented in Table 1. Statistically significant differences between obese and normal-weight youth were found in age, BMI, and the presence of comorbid conditions. Small-to-medium correlations between socio-demographic and study variables were found (Table 2).

The indirect effect of weight status on youth's psychosocial adjustment through body image dissatisfaction

Three moderated mediation models were estimated (Fig. 1). The final models are presented in Fig. 2, and the model coefficients for the direct and indirect effects are presented in Table 3. The presence of comorbidities was entered as a covariate.

\section{Quality of life}

With regard to QOL, no significant interactions were found between gender and weight status in paths $a$ and $c^{\prime}$ and between gender and BID in path $b$. Therefore, the model was re-estimated after the removal of gender. In the final model, the interaction between age and weight status was significant $(b=-0.12, p=.003)$, as was the interaction between age and BID $(b=-0.63, p=.028)$. With evidence that paths $a$ and $b$ were moderated by age, we subsequently estimated the conditional indirect effects at each percentile of age (Table 3). Based on $95 \%$ bootstrap BCaCIs, significant indirect effects were found among youth aged 12-, 15-, and 17-year old. With regard to the direct effect of weight status on QOL, the conditional direct effects were only significant among children aged 8.

\section{Psychological functioning}

In both models of internalizing and externalizing problems, the only significant interaction was in path $a$ (age $\times$ weight status). After the removal of the nonsignificant interactions, the final models evidenced no significant conditional indirect effects at any level of the youth's age. The analysis of individual paths showed that BID was not significantly associated with internalizing and externalizing problems, although the direct effect of weight status on the DVs was significant. In all models, being obese was associated with higher levels of BID.

The moderating role of youth's age on the link between weight status and BID

The interaction found between age and weight status in path $a$ was probed by estimating the conditional effect of weight status on BID at the values of the youth's ages corresponding to the 10th, 25th, 50th, 75th, and 90th percentiles in the sample distribution of age. Weight status was significantly related to BID at all ages, with obese 
Model 1: Quality of Life

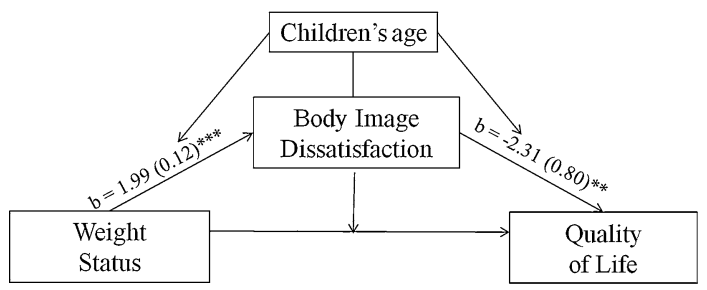

Model 2: Internalizing Problems

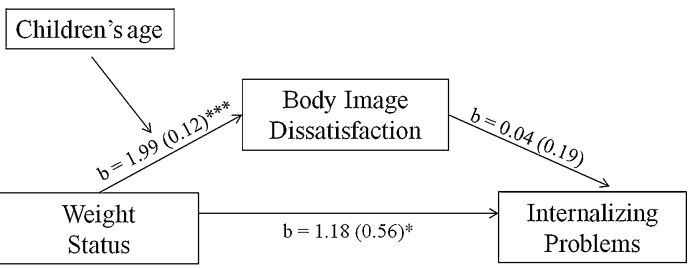

Model 3: Externalizing Problems

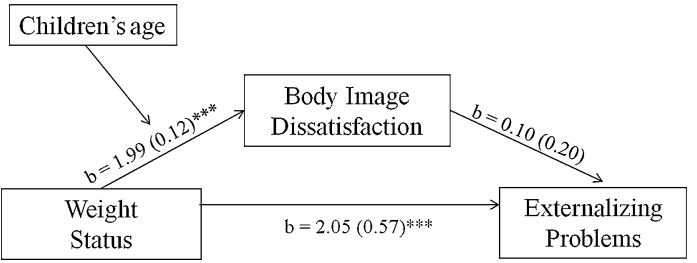

Fig. 2 Statistical diagram of the three moderated mediating models estimated (QOL, internalizing and externalizing problems). Note Path values represent unstandardized regression coefficients, and the values inside the parenthesis represent the standard errors. Because path $a$ is moderated by age in all models, regression coefficients differ in each percentile of age $(2.51,2.28,2.05,1.70,1.46$ in percentiles 10 , $25,50,75,90$, respectively; see Table 4). Similarly, because path $b$ is moderated by age in model 1, regression coefficients at different percentiles of age are $-1.17,-1.64,-2.12,-2.83$, and -3.31 (percentiles 10, 25, 50, 75, 90, respectively). Conditional direct effects for Model 1 are provided in Table $3 .{ }^{*} p<.05 ; * * p<.01$; $* * * p<.001$

youth exhibiting higher levels of BID (Table 4). Figure 3 plots the conditional effect of the weight status on BID across the distribution of youth's ages. Among obese youth, BID tended to decrease as age increased, whereas an inverse pattern was found among normal-weight youth.

\section{Discussion}

The results of the present study suggest that obese youth, regardless of gender, have greater impairment in their psychosocial adjustment and greater dissatisfaction with their body image than their normal-weight peers. This study also demonstrates that for adolescents, dissatisfaction with body image is an important mechanism that may underlie the association between weight status and QOL. Conversely, the link between weight status and internalizing/externalizing problems is direct and independent of youth's age.

As expected, obese youth reported worse QOL and higher levels of psychological problems than their normalweight peers. Similar findings have been identified in several studies [4-6, 17, 20,24], suggesting a consistent relationship between obesity and poorer psychosocial outcomes. This finding may be due to psychosocial stressors, such as the higher rates of social rejection, stigmatization, and weight victimization obese youth frequently face [79]. Nevertheless, we should note that in our sample, the reported means of psychological problems were relatively low (i.e., ranging from 4.71 to 6.81 in a possible range of $0-20$ ), suggesting the presence of subclinical levels of internalizing/externalizing problems in obese youth.

With regard to BID, our findings confirmed the results obtained in previous investigations [28-30] by demonstrating that obese youth were more dissatisfied with their appearance than their normal-weight counterparts across all age levels. This is an expected result given the social stigma associated with obesity [28-30]. Youth with obesity are likely to be exposed to "anti-fat messages" [33], peer teasing, or negative social comparisons, which may lead them to feel a strong dissatisfaction with their body from an early age.

An interesting finding was that although we identified a moderating effect of youth's age on the association between weight status and BID, this association was significant at all age levels, although it presented a different pattern between groups. Obese youth exhibited a slight decrease in their BID as age increased, whereas normalweight youth exhibited a slight increase, except between the ages of 10 and 12 years. Although these results should be interpreted cautiously because of the cross-sectional design of the study, the suggestion that obese children may report higher levels of BID than obese adolescents is an unexpected finding. As found in the normal-weight group, it would be expected that during adolescence, weight concerns would become more salient [34]. It is possible that obese children report increased BID because they are beginning to be confronted with the negative social repercussions of their weight, in contrast to adolescents, who may have been obese for several years and may have developed strategies to address their appearance (e.g., acceptance of their physical appearance, ignoring verbal insults, or avoiding certain social interactions). However, to understand the developmental progression of BID over time and to identify possible mechanisms that contribute to BID at different developmental stages, it would be indispensable to implement a longitudinal design.

One of the major goals of this study was to explore the mediating role of BID in the association between weight status and youth's adjustment. Contrary to our hypothesis, 
Table 3 Model coefficients for the conditional process models presented in Fig. 2

\begin{tabular}{|c|c|c|c|c|}
\hline \multirow[t]{2}{*}{ Youth's age } & \multicolumn{2}{|c|}{ Direct effect $\left(c^{\prime}\right)$} & \multicolumn{2}{|c|}{ Indirect effect $\left(a^{*} b\right)$} \\
\hline & $b(\mathrm{SE})$ & $p$ & $b(\mathrm{SE})$ & $\begin{array}{l}95 \% \text { Bias-corrected } \\
\text { bootstrap CI } \\
\text { (LLCI; ULCI) }\end{array}$ \\
\hline \multicolumn{5}{|c|}{ Model 1: QOL (years) } \\
\hline 8 & $-8.46(4.22)$ & .046 & $1.36(3.65)$ & -5.24 to 9.18 \\
\hline 10 & $-5.69(3.03)$ & .061 & $-1.65(2.30)$ & -5.93 to 3.09 \\
\hline 12 & $-2.91(2.26)$ & .199 & $-4.08(1.66)$ & -7.24 to -0.73 \\
\hline 15 & $1.24(2.75)$ & 652 & $-6.61(2.05)$ & -10.77 to -2.70 \\
\hline 17 & $4.02(3.86)$ & .299 & $-7.56(2.56)$ & -13.19 to -3.01 \\
\hline \multicolumn{5}{|c|}{ Model 2: Internalizing problems (years) } \\
\hline 8 & $1.18(0.56)$ & .035 & $0.11(0.57)$ & -1.01 to 1.21 \\
\hline 10 & & & $0.10(0.51)$ & -0.91 to 1.10 \\
\hline 12 & & & $0.09(0.46)$ & -0.81 to 0.99 \\
\hline 15 & & & $0.07(0.38)$ & -0.67 to 0.83 \\
\hline 17 & & & $0.06(0.33)$ & -0.58 to 0.74 \\
\hline \multicolumn{5}{|c|}{ Model 3: Externalizing problems (years) } \\
\hline 8 & $2.05(0.57)$ & $<.001$ & $0.25(0.54)$ & -0.75 to 1.35 \\
\hline 10 & & & $0.23(0.49)$ & -0.69 to 1.21 \\
\hline 12 & & & $0.21(0.44)$ & -0.62 to 1.08 \\
\hline 15 & & & $0.17(0.36)$ & -0.52 to 0.89 \\
\hline 17 & & & $0.15(0.31)$ & -0.45 to 0.78 \\
\hline
\end{tabular}

$S E$ standard error; $C I$ confidence interval, $L L C I$ lower-limit confidence interval, $U L C I$ upper-limit confidence interval. All coefficients are unstandardized

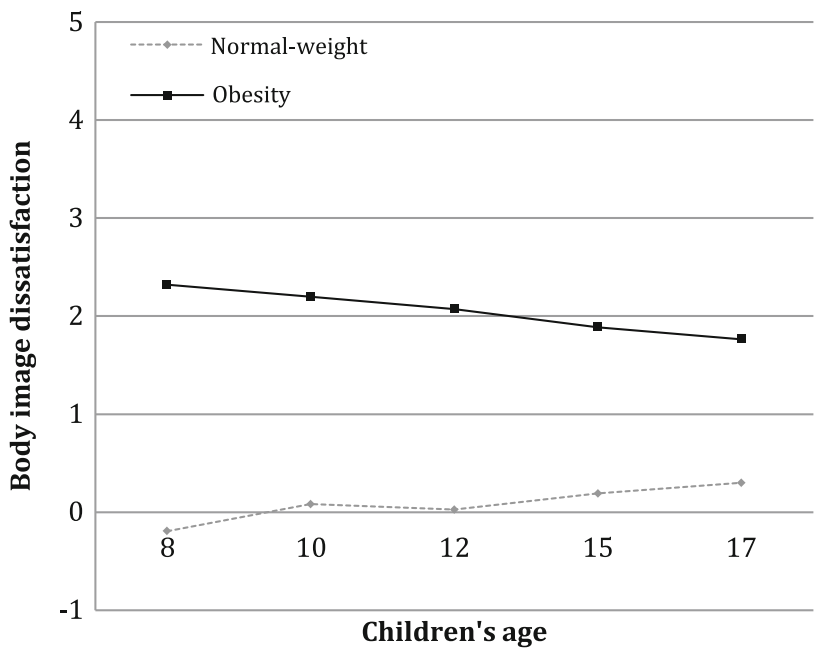

Fig. 3 The moderation of the effect of weight status on BID by youth's age

cycles of schooling. School transitions are periods of potential stress and increased vulnerability because of the multiple social and academic challenges which pre-adolescents may face (e.g., new friends, higher autonomy [53]). During this transition period, the need to belong and to fit into a new context may increase, and social acceptance and friendships may assume central roles. Therefore, it is not surprising that body image becomes particularly salient, serving as a potential mechanism linking obesity to 
lower levels of QOL. For children aged 8 years or younger, being obese was directly related to lower QOL, independent of their BID. This finding suggests that appearance concerns are not central aspects of children's QOL, even though these concerns might be present at an early development stage.

Conditional process analyses also showed that obese youth exhibited higher levels of internalizing and externalizing problems regardless of their BID. Moreover, BID was not significantly associated with these psychological problems, which is inconsistent with the previous findings showing that obese youth with high levels of appearance concerns are at increased risk of psychological maladjustment $[30,44]$. This result suggest that BID is not a central issue in the youth's psychological functioning and that there may be other mechanisms that better explain why they present more psychological problems (e.g., emotion regulation processes, dysfunctional family environments). Moreover, it is important to note that path $b$ quantifies how much two cases that differ by one unit on BID but that are equal on weight status are estimated to differ in internalizing/externalizing problems. Because weight status is held constant, we cannot ascertain whether BID would have had a different effect if each group were analyzed separately.

Finally, youth's gender did not moderate the proposed associations, meaning that this model works similarly for boys and girls. This could be considered an unexpected finding given the gender differences on BID reported in previous studies, with girls reporting higher levels of BID than boys [33, 37]. Nevertheless, it should be emphasized that the absence of a moderating effect of gender is not the same as the absence of gender differences. This study was designed to test a moderated mediating model, meaning that conclusions from previous comparison studies cannot be directly applied.

Some limitations of this study should be noted. First, the cross-sectional design precludes the possibility of establishing causal relationships. Second, the lack of a nontreatment-seeking sample of obese youth did not permit us to ascertain whether the results could be explained only by weight or by treatment-seeking status. Third, the representativeness of our sample can be questioned because participants were selected from public hospitals and schools in a specific region of Portugal. Fourth, the length of treatment before youth participated in the current study was not available for most participants and therefore was not reported. Fifth, two different sample collection procedures were used. Consequently, the weight and height of obese youth were measured objectively by the nutritionist, whereas the weight and height of normal-weight participants were measured subjectively - that is, they were self-reported by the parents of children under 14 years and by adolescents. This is an important limitation because several studies have demonstrated that youth may not be able to accurately selfreport their weight and height [54-56]. Sixth, there are no Portuguese norms available for the SDQ. Therefore, the clinical relevance of findings obtained with this questionnaire should be interpreted cautiously. Finally, although the Collins Body Image Scale [51] has been commonly used and is considered an appropriate measure for assessing BID in youth (because of its easiness, nondependence on verbal skills, and visual appeal [57]), it has some limitations. For instance, it has been argued that pictorial measures are unrealistic representations of the human form, lack robust psychometric data, and present weak correlations between current self-ratings and youth's BMI $[57,58]$. It has also been argued that these measures do not allow the assessment of body size distortion and do not provide information about the accuracy of perceptions of current height and weight [58]. Although some studies have demonstrated that youth are able to provide an accurate assessment of their body size from an early age [59], others have demonstrated that they are poor self-reporters of their weight and height [54-56], which may hinder an accurate assessment of their body silhouette.

Despite these limitations, this study has several strengths. To our knowledge, this is the first study to explore the mediating role of BID on the associations between weight and the youth's psychosocial adjustment. This study is also innovative because it adopts a developmental perspective by exploring the moderating effect of youth's age. Other methodological strengths are the use of two distinct indicators of psychosocial adjustment and the use of self-reported instruments rather than parent proxy reports, prioritizing youth' self-evaluation and avoiding biases from others' evaluations of the youth's psychosocial adjustment. These findings also have important practical implications. The poorer psychosocial adjustment and higher levels of BID of obese boys and girls highlight the need for prevention and early intervention. It is essential for these youth to be treated in multidisciplinary teams that include pediatric mental health professionals able to assess and identify psychosocial difficulties and needs, in order to provide appropriate psychological interventions. Screening youth's level of BID can be important to tailor interventions and to decide when to use strategies aimed at improving youth's satisfaction with appearance, which may have significant positive repercussions on their QOL. This study suggests that for younger children, the inclusion of body imagerelated issues in psychosocial interventions may not be as important as for pre-adolescents and adolescents, and therefore, other mechanisms should be explored. 
Nevertheless, this does not mean that children should not be screened for BID. In fact, children who experience high levels of BID at younger ages may also benefit from interventions to improve their satisfaction with their appearance, preventing elevated rates of BID and other psychosocial impairments in adolescence. In conclusion, the psychosocial needs of obese youth should not be neglected, especially because it is well recognized that better adjustment may diminish the likelihood of obesity and further complications in adulthood [6,9].

Acknowledgments This work was partially supported by the Portuguese Foundation for Science and Technology [SFRH/BPD/70063/ 2010].

\section{References}

1. Currie, C., Zanotti, C., Morgan, A., Currie, D., Looze, M., Roberts, C., et al. (Eds.). (2012). Social determinants of health and well-being among young people. Health Behaviour in School-aged Children (HBSC) study: International report from the 2009/2010 survey. Copenhagen: WHO Regional Office for Europe (Health Policy for Children and Adolescents, No. 6).

2. Steele, R. G., Nelson, T. D., \& Jelalian, E. (2008). Pediatric obesity: Trends and epidemiology. In E. Jelalian \& R. Steele (Eds.), Handbook of childhood and adolescent obesity (pp. 3-10). New York: Springer.

3. Vivier, P., \& Tompkins, C. (2008). Health consequences of obesity in children and adolescents. In E. Jelalian \& R. Steele (Eds.), Handbook of childhood and adolescent obesity (pp. 11-24). New York: Springer.

4. Riazi, A., Shakoor, S., Dundas, I., Eiser, C., \& McKenzie, S. (2010). Health-related quality of life in a clinical sample of obese children and adolescents. Health and Quality of Life Outcomes, 8 , 134. doi:10.1186/1477-7525-8-134.

5. Wille, N., Bullinger, M., Holl, R., Hoffmeister, U., Mann, R., Goldapp, C., et al. (2010). Health-related quality of life in overweight and obese youths: Results of a multicenter study. Health and Quality of Life Outcomes, 8, 1-8. doi:10.1186/14777525-8-36.

6. Zeller, M. H., \& Modi, A. C. (2008). Psychosocial factors related to obesity in children and adolescents. In E. Jelalian \& R. Steele (Eds.), Handbook of childhood and adolescent obesity (pp. 25-42). New York: Springer.

7. Latner, J. D., \& Stunkard, A. J. (2003). Getting worse: The stigmatization of obese children. Obesity Research, 11, 452-456. doi:10.1038/oby.2003.61.

8. Puhl, R. M., \& Latner, J. D. (2007). Stigma, obesity, and the health of the nation's children. Psychological Bulletin, 133, 557-580. doi:10.1037/0033-2909.133.4.557.

9. Jelalian, E., \& Hart, C. N. (2009). Pediatric obesity. In M. C. Roberts \& R. G. Steele (Eds.), Handbook of pediatric psychology (pp. 446-463). New York: The Guilford Press.

10. Zeller, M. H., Reiter-Purtill, J., \& Ramey, C. (2008). Negative peer perceptions of obese children in the classroom environment. Obesity, 14, 755-762. doi:10.1038/oby.2008.4.

11. Jensen, C. D., \& Steele, R. G. (2012). Longitudinal associations between teasing and health-related quality of life among treatment-seeking overweight and obese youth. Journal of Pediatric Psychology, 37, 438-447. doi:10.1093/jpepsy/jsr108.
12. Ottova, V., Erhart, M., Rajmil, L., Dettenborn-Betz, L., \& Ravens-Sieberer, U. (2012). Overweight and its impact on the health-related quality of life in children and adolescents: Results from the European KIDSCREEN survey. Quality of Life Research, 21, 59-69. doi:10.1007/s11136-011-9922-7.

13. Pinhas-Hamiel, O., Singer, S., Pilpel, N., Fradkin, A., Modan, D., \& Reichman, B. (2006). Health-related quality of life among children and adolescents: Associations with obesity. International Journal of Obesity, 30, 267-272. doi:10.1038/sj.ijo.0803107.

14. Swallen, K. C., Reither, E. N., Haas, S. A., \& Meier, A. M. (2005). Overweight, obesity, and health-related quality of life among adolescents: The national longitudinal study of adolescent health. Pediatrics, 115, 340-347. doi:10.1542/peds.2004-0678.

15. Puder, J., \& Munsch, S. (2010). Psychological correlates of childhood obesity. International Journal of Obesity, 34, 37-43. doi:10.1038/ijo.2010.238.

16. Zeller, M. H., Saelens, B. E., Roehrig, H., Kirk, S., \& Daniels, S. R. (2004). Psychological adjustment of obese youth presenting for weight management treatment. Obesity Research, 12, 1576-1586.

17. Zeller, M. H., \& Modi, A. C. (2006). Predictors of health-related quality of life in obese youth. Obesity, 14, 122-130. doi:10.1038/ oby.2006.15.

18. Schwimmer, J. B., Burwinkle, T. M., \& Varni, J. W. (2003). Health-related quality of life of severely obese children and adolescents. Journal of the American Medical Association, 289, 1813-1819.

19. Zeller, M. H., Roehrig, H. R., Modi, A. C., Daniels, S. R., \& Inge, T. H. (2006). Health-related quality of life and depressive symptoms in adolescents with extreme obesity presenting for bariatric surgery. Pediatrics, 117, 1155-1161. doi:10.1542/peds. 2005-1141.

20. Moreira, H., Carona, C., Silva, N., Frontini, R., Bullinger, M., \& Canavarro, M. C. (in press). Psychological and quality of life outcomes in pediatric populations: A parent-child perspective. Journal of Pediatrics. doi:10.1016/j.jpeds.2013.06.028.

21. Braet, C., Mervielde, I., \& Vandereycken, W. (1997). Psychological aspects of childhood obesity: A controlled study in a clinical and nonclinical sample. Journal of Pediatric Psychology, 22, 59-71.

22. Britz, B., Siegfried, W., Ziegler, A., Lamertz, C., HerpertzDahlamann, B. H., Remschmidt, H., et al. (2000). Rates of psychiatric disorders in a clinical study group of adolescents with extreme obesity and in obese adolescents ascertained via a population based study. International Journal of Obesity, 24, $1707-1714$

23. Vila, G., Zipper, E., Dabbas, M., Bertrand, C., Robert, J. J., Ricour, C., et al. (2004). Mental disorders in obese children and adolescents. Psychosomatic Medicine, 66, 387-394.

24. Lawlor, D. A., Mamum, A. A., O'Callaghan, M. J., Bor, W., Williams, G. M., \& Najman, J. M. (2005). Is being overweight associated with behavioral problems in childhood and adolescence? Findings from the mater-university study of pregnancy and its outcomes. Archives of Disease in Childhood, 90, 692-697. doi:10.1136/adc.2004.062919.

25. Mustillo, S., Worthman, C., Erkanli, A., Keeler, G., Angold, A., \& Costello, E. J. (2003). Obesity and psychiatric disorder: Developmental trajectories. Pediatrics, 111, 851-859. doi:10. 1542/peds.111.4.851.

26. Datar, A., \& Sturm, R. (2006). Childhood overweight and elementary school outcomes. International Journal of Obesity, 30, 1449-1460. doi:10.1038/sj.ijo.0803311.

27. Falkner, N. H., Neumark-Sztainer, D., Story, M., Jeffery, R. W., Beuhring, T., \& Resnick, M. D. (2001). Social, educational and psychological correlates of weight status in adolescents. Obesity Research, 9, 32-42. doi:10.1038/oby.2001.5. 
28. Loth, K. A., Mond, J., Wall, M., \& Neumark-Sztainer, D. (2011). Weight status and emotional well-being: Longitudinal findings from project EAT. Journal of Pediatric Psychology, 36, 216-225. doi:10.1093/jpepsy/jsq026.

29. Neumark-Sztainer, D. (2011). Obesity and body image in youth. In T. F. Cash \& L. Smolak (Eds.), Body image: A handbook of science, practice and prevention (pp. 180-189). New York: The Guilford Press.

30. Shin, N. Y., \& Shin, M. S. (2008). Body dissatisfaction, selfesteem, and depression in obese Korean children. Journal of Pediatrics, 152, 502-506. doi:10.1016/j.jpeds.2007.09.020.

31. Pinquart, M. (2013). Body image of children and adolescents with chronic illness: A meta-analytic comparison with healthy peers. Body Image, 10, 141-148. doi:10.1016/j.bodyim.2012.10. 008.

32. Smolak, L., \& Levine, M. P. (2001). Body image in children. In J. K. Thompson \& L. Smolak (Eds.), Body image, eating disorders, and obesity in youth: Assessment, prevention, and treatment (pp. 41-66). Washington, DC: American Psychological Association.

33. Smolak, L. (2011). Body image development in childhood. In T. F. Cash \& L. Smolak (Eds.), Body image: A handbook of science, practice and prevention (pp. 180-189). New York: The Guilford Press.

34. Wertheim, E. H., \& Paxton, S. J. (2011). Body image development in adolescent girls. In T. F. Cash \& L. Smolak (Eds.), Body image: A handbook of science, practice and prevention (pp. 76-84). New York: The Guilford Press.

35. Ricciardelli, L. A., \& McCabe, M. P. (2011). Body image development in adolescent boys. In T. F. Cash \& L. Smolak (Eds.), Body image: A handbook of science, practice and prevention (pp. 85-92). New York: The Guilford Press.

36. Rosenblum, G. D., \& Lewis, M. (1999). The relations among body image, physical attractiveness, and body mass in adolescence. Child Development, 70, 50-64.

37. Wertheim, E. H., Paxton, S. P., \& Blaney, S. (2009). Body image in girls. In L. Smolak \& J. K. Thompson (Eds.), Body image, eating disorders, and obesity in youth: Assessment, prevention, and treatment (pp. 47-76). Washington, DC: American Psychological Association.

38. Cohane, G. H., \& Pope, H. G. (2001). Body image in boys: A review of the literature. International Journal of Eating Disorders, 29, 373-379. doi:10.1002/eat.1033.

39. Jones, D. C., Bain, N., \& King, S. (2008). Weight and muscularity as longitudinal predictors of body image among early adolescent boys: A test of the dual pathway model. Body Image, 5, 195-204. doi:10.1016/j.bodyim.2007.12.001.

40. Stice, E. (2002). Risk and maintenance factors for eating pathology: A meta-analytic review. Psychological Bulletin, 128, 825-848. doi:10.1037/0033-2909.128.5.825.

41. Smolak, L., \& Thompson, J. K. (2009). Body image, eating disorders, and obesity in children and adolescents: Introduction to the second edition. In L. Smolak \& J. K. Thompson (Eds.), Body image, eating disorders, and obesity in youth: Assessment, prevention, and treatment (pp. 1-14). Washington, DC: American Psychological Association.

42. Kostanski, M., \& Gullone, E. (1998). Adolescent body image dissatisfaction: Relationships with self-esteem, anxiety, and depression controlling for body mass. Journal of Child Psychology and Psychiatry, 39, 255-262. doi:10.1111/1469-7610. 00319.

43. Doyle, A. C., Le Grange, D., Goldschmidt, A., \& Wilfley, D. E. (2007). Psychosocial and physical impairment in overweight adolescents at high risk for eating disorders. Obesity, 15, 145-154. doi:10.1038/oby.2007.515.

44. Allen, K. L., Byrne, S. M., Blair, E. M., \& Davis, E. A. (2006). Why do some overweight children experience psychological problems? The role of weight and shape concern. International Journal of Pediatric Obesity, 1, 239-247. doi:10.1080/ 17477160600913552.

45. Kuczmarski, R. J., Ogden, C. L., Guo, S. S., Grummer-Strawn, L. M., Flegal, K. M., Mei, Z., et al. (2002). 2000 CDC growth charts for the United States: Methods and development. Vital Health Statistics, 11(246), 1-190.

46. Gaspar, T., \& Matos, M. G. (2008). Qualidade de vida em crianças e adolescentes: Versão portuguesa dos instrumentos KIDSCREEN-52 [quality of life in children and adolescents: Portuguese version of the instruments KIDSCREEN-52]. Cruz Quebrada: Aventura Social e Saúde.

47. Ravens-Sieberer, U., Erhart, M., Rajmil, L., Herdman, M., Auquier, P., Bruil, J., et al. (2010). Reliability, construct and criterion validity of the KIDSCREEN-10 score: A short measure for children and adolescents' well-being and health-related quality of life. Quality of Life Research, 19, 1487-1500. doi:10.1007/ s11136-010-9706-5.

48. Fleitlich, B., Loureiro, M., Fonseca, A., \& Gaspar, M. (2005). Questionário de capacidades e de dificuldades (SDQ-Por) [strenghts and difficulties questionnaire, Portuguese version]. Retrived from www.sdqinfo.org.

49. Goodman, R. (2001). Psychometric properties of the strengths and difficulties questionnaire. Journal of the American Academy of Child and Adolescent Psychiatry, 40, 1337-1345. doi:10.1097/ 00004583-200111000-00015.

50. Goodman, A., Lamping, D., \& Ploubidis, G. B. (2010). When to use broader internalizing and externalizing subscales instead of the hypothesized five subscales on the strengths and difficulties questionnaire (SDQ): Data from British parents, teachers and children. Journal of Abnormal Child Psychology, 38, 1179-1191. doi:10.1007/s10802-010-9434-x.

51. Collins, M. E. (1991). Body figure perceptions and preferences among preadolescent children. International Journal of Eating Disorders, 10, 199-208. doi:10.1002/1098-108X(199103).

52. Hayes, A. F. (2013). Introduction to mediation, moderation, and conditional process analysis: A regression-based approach. New York: The Guilford Press.

53. Cantin, S., \& Boivan, M. (2004). Change and stability in children's special network and self-perceptions during transition from elementary to junior high school. International Journal of Behavioral Development, 28, 561-570. doi:10.1080/ 01650250444000289

54. Brener, N. D., McManus, T., Galuska, D. A., Lowry, R., \& Wechsler, H. (2003). Reliability and validity of self-reported height and weight among high school students. Journal of Adolescent Health, 32, 281-287. doi:10.1016/S1054-139X(02)00708-5.

55. Tokmakidis, S. P., Christodoulos, A. D., \& Mantzouranis, N. I. (2007). Validity of self-reported anthropometric values used to assess body mass index and estimate obesity in Greek school children. Journal of Adolescent Health, 40, 305-310. doi:10. 1016/j.jadohealth.2006.10.001.

56. Beck, J., Schaefer, C. A., Nace, H., Steffen, A. D., Nigg, C., Brink, L., et al. (2012). Peer reviewed: Accuracy of self-reported height and weight in children aged 6 to 11 years. Preventing Chronic Disease, 9, E119. doi:10.5888/pcd9.120021.

57. Hill, A. J. (2011). Body image assessment of children. In T. F. Cash \& L. Smolak (Eds.), Body image: A handbook of science, practice and prevention (pp. 138-145). New York: The Guilford Press.

58. Gardner, R. M., \& Brown, D. L. (2010). Body image assessment: A review of figural drawing scales. Personality and Individual Differences, 48(2), 107-111. doi:10.1016/j.paid.2009.08.017.

59. Gardner, R. M., Sorter, R. G., \& Friedman, B. N. (1997). Developmental changes in children's body images. Journal of Social Behavior and Personality, 12, 1019-1036. 